\title{
Observations on Death and Life of Public Space in Australia during the COVID- 19 Pandemic
}

\author{
Gregor H. Mews \\ Queensland University of Technology, Australia \\ Gregor.Mews@qut.edu.au \\ Milica Muminovic \\ University of Canberra, Australia \\ milica.muminovic@canberra.edu.au
}

\begin{abstract}
"Do not touch me, touch and deal with other people in the spirit of love" is stated upfront in Zizek (2020) recent reflection on the unprecedented global pandemic that has a firm grip on our societies. The quote makes two strong points that highlight the essence of this commentary. First, it implies that during the global COVIDI9 pandemic each and every one of use is forced to deal with their on human spirit embodied through the ontological state of existence and apply mindfulness and accountability for their actions in their everyday life routines. Second, public life in cities is different. Quickly the 'new normal' dictates our everyday life routines while systemic spatial issues being amplified, while social distancing measures are in place and restriction on social encounter being enforced. We present an argument that is based on direct observations of lockdown conditions during the first wave in 2020 in the Australian context. Careful framing around the concepts of 'urban loveability' and public space allows us to critically examine the synergy between aspects of the human spirit that celebrate and unite us. Whether the 'new normal' embraces death or life is evident if we pay attention to detailed traces of dynamic and intangible elements in public spaces. They remind us what makes us human and holding the possibility to realise a new ontological state of existence.
\end{abstract}

Keywords: public space, COVIDI9 pandemic, new normal, urban loveability, Australia

To cite this article:

Mews, G., Muminovic, M. (2020). Observations on Death and Life of Public Space in Australia during the COVID-19 Pandemic, The Journal of Public Space, 5(3), I73-182, DOI

I0.3289I/jps.v5i3.1366

This article has been double blind peer reviewed and accepted for publication in The Journal of Public Space. (C) This work is licensed under a Creative Commons Attribution - Non Commercial 4.0 International License https://creativecommons.org/licenses/by-nc/4.0/ 
The degree, speed and level of impact of the COVID-I9 is vast and affects all pores of people's everyday life across the world, such that soon it became the 'new normal'. We argue that it is important to capture those associated changes, thus with this article we seek to report on traces of everyday life that can be detected in public space as a result of the looser stages of social distancing (also referred to as physical distancing) under lockdown conditions early 2020. Those observations are providing room for a discourse that allows us to negotiate ways into a different public space culture that celebrates public life in cities and enables a renegotiation of new boundary conditions of social production of spaces.

Mumford's classic account from 1937 on what cities ought to be- namely a conscious work of art embedded within a communal framework in which personalised forms of art are manifested and celebrated with others can serve as a practical orientation (Mumford, 2016). Recent academic discussions on public spaces and their roles in the cities have reported the need to redefine the public space and its role in public life (Amin, 2008; Madanipour, 2019). In addition, the value of capturing people's everyday life experiences in neighbourhoods as a mean to enable transformational change has been realised since the pioneering work by Jacobs (196I). This concept is further developed within the approach of 'urban loveability' (Ottosen and Mews, 2019; Mews, 2020) that imbues public spaces with new life and allows us to observe the birth of positive meaning through co-produced spaces that truly appreciate and celebrate the value of public life in cities. Consequently, this contribution observes how those traces of everyday life generate new manifestations of connection between the individual and public space under conditions of social distancing. By applying the diary method (Gehl et al., 2013) and direct observation during the first wave in April to March 2020, we report on the changes observed since the introduction of social distancing during regular visits to public spaces in two Australian cities, countries (Ngunnawal Country where Canberra is situated and Jagera and Turrabal country where Brisbane now stands on).

\section{A critical remark on the 'before' and the 'new normal'}

The phrase 'new normal' and its associated human conditions are considered as a baseline in immediate response to the lasting impacts of the COVID-I 9 pandemic globally. Since the start of the initial lockdown waves people across all ages utilise social media to communicate personal stories and individualised perspectives on how this "new normal' impacts their everyday life and how to celebrate breaks of the habitus that dominates human behaviour under lockdown conditions. An observable commonality is that the reporting contains a description of 'everyday life' and in most cases how that relates to the appreciation of public life in cities. When interrogating public space data framed around concepts such as commodification, value, and different forms of spatial practices associated with alienation and separation then, we argue that everyday life during the 'new normal' before the rollout of the vaccine allows us to engage in a discourse that overrides the dominant Keynesian and neoliberal paradigm in various forms and shapes. Noticeably these paradigms gave rise to the private sector enabling conditions in which spaces for public everyday life are produced that focus on the targeted distribution of resources and intervention in favour of capital accumulation (Butler, 2012, Lefebvre, 199I, Harvey, 1985). Australian capital cities demonstrate a plethora of different case studies that are a testimony of such conditions (Farrelly, 
202I). Privatisation of public spaces and programming in pursuit of unbalanced capital accumulation became an inescapable means to connect to other people (Madanipour, 2019) as privately managed public spaces are often the only places available and can afford public liability insurances that allow for the programmed celebration of public space for certain user groups. For example, from a place-making perspective, most public administrations across Australia operate within a 'risk averse' operation paradigm that in consequence discourages, suppresses, and in fact inhibits dynamic ad-hoc initiative and space appropriation that overrides capital accumulation by embracing diversity and possibility that imbue public space with social life.

The idea of welcoming uncertainty through a sense of discovery and adventure by consciously escaping or even breaking the prevalent paradigm is not yet new. The Situationist International created a movement framed around The Spectacle (Debord, 1983, Debord, 1957). The Spectacle reveals itself within the manifestation of news, advertisement, entertainment and of course through consumption and capital accumulation. Everyday life in relation to public space in its broadest sense defines how we interact with the city. There are two important aspects of this everyday life, firstly it takes most of our time thus represents an important part of our lives and secondly, this everydayness disappears in the repetition, the normal, the mundane and thus the insignificance of a routine (Lefebvre, 1991). The way we can become aware of this 'normal' is in the creation of new situations distancing us from these repetitive and ordinary activities (Perec, 2008, p. 210). Thus, the 'new normal' created with the current condition of pandemic represents an opportunity to review the everyday life and the role of public space. Arguably, applying such a conceptual window to data related to everyday life in contemporary Australia, is highly relevant today as it allows us to understand the impact of spatial practices that override neoliberal conditions under lockdown conditions. The new normal offers a new 'situation' and opportunity to discuss the new view on the ordinary public spaces, often considered underutilised and emerging traces of the public life in such spaces.

Therefore, this commentary examines and reports on public space conditions to better understand and conceive the city as a piece of art in which the hope to overcome fecklessness through co-production of spaces that celebrate everyday life beyond alienation and separation ought to be obtainable. Based on this critical remark and the abrupt death of public everyday life as we know it, we pay attention to what currently unfolds across many local neighbourhoods across Australia. Observations of everyday life in public spaces in Brisbane and Canberra illustrate the break from the conditioning before the COVID-19 pandemic during the first wave of government restrictions in 2020. The Australian Government adopted a number of restrictions that came into effect from the $20^{\text {th }}$ March (Australian Government). Most people were forced to work from home and only allowed to appropriate public space for essential trips and errands, locally within their respected neighbourhood. Residents were able to engage in public space only to service everyday life necessities, namely food consumption, domestic materials and utilities and recreation. A stark rise in unemployment, reported cases of anxiety, stress and gender-based violence are some of the consequences. The rule of social distancing a minimum of 1.5 metres and limited access to markets is strictly enforced. Public institutions, pubs and restaurants remained closed or were only allowed to operate with home delivery options. Mail services were disrupted while international and interstate travel is still not possible. With respect to facilities in public 
Observations on Death and Life of Public Space in Australia during the COVID-19 Pandemic

spaces such as national parks, campgrounds, playgrounds, dog parks, beaches, exercise stations and BBQ areas remained closed during the lockdown (Figure I and 2).

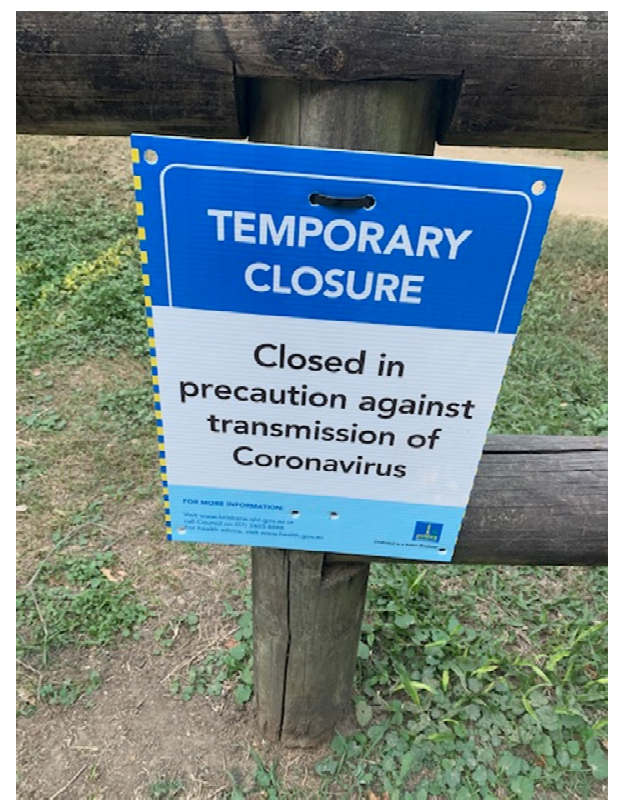

Figure I. Public space closure sign by Brisbane City Council (Source: Gregor Mews)

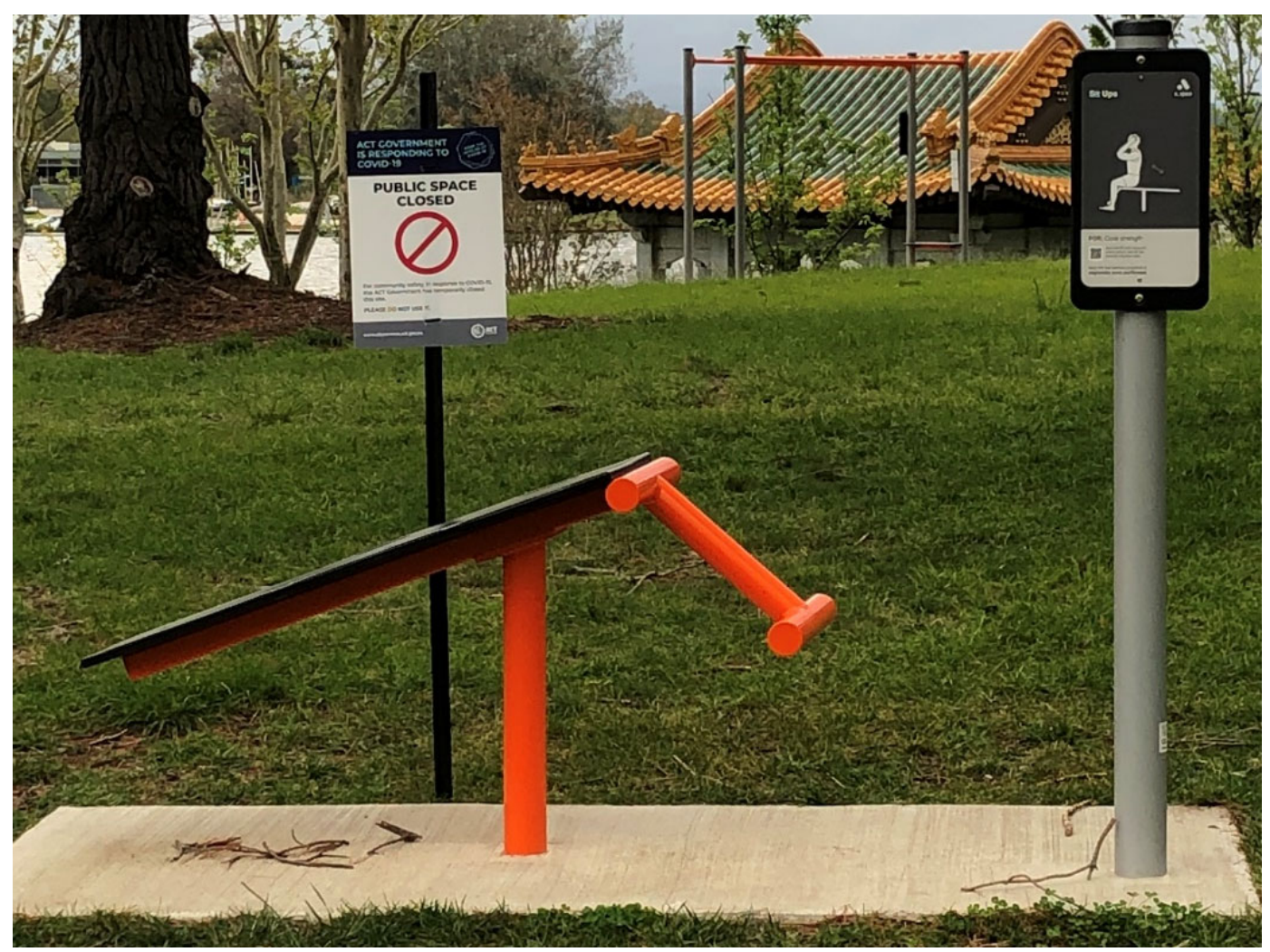

Figure 2. Public space closure sign by ACT Government (Source: Milica Muminovic) 
The new environmental conditions enabled people to co-produce spaces in a hyperlocalised sense and outside of their previously commodified state of existence. 'Hyper' due to the physical distancing policies, and 'localised' caused by the spatial movement restrictions, people start to rediscover their neighbourhood. Meanwhile, Australia wide data confirmed that mobility (walking and cycling) rates have increased on average up to 17- 34 percent compared to previous levels across the neighbourhoods (Google, 2020). At the same time retail visits have decreased by 24-33 percent (Google, 2020).

\section{Observations from Jagera and Turrabal country/ Brisbane}

Jagera and Turrabal country where Brisbane is situated is now the third most populated state capital city in Australia and one of the oldest cities on the continent that has been in the making on the homeland of the Turrabal and Jagera people. Currently around 2.4 million people call subtropical Brisbane their home and imbue life to public spaces in various ways (Population Australia, 2020).

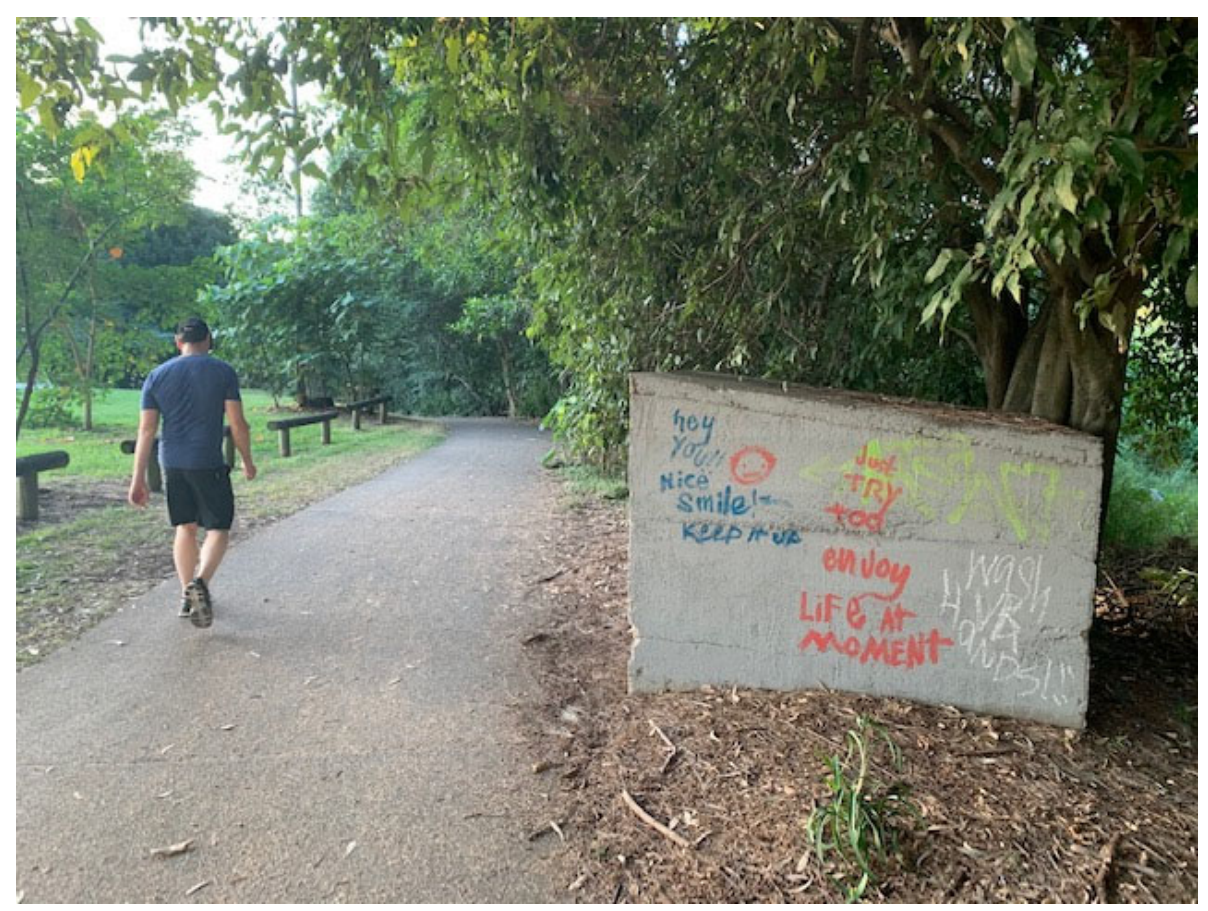

Figure 3. Images with positive messages (Source: Gregor Mews)

Apart from the Central Business District, most people spend their everyday life in suburban neighbourhoods in this subtropical environment and the enforced social distancing policies, or preferred physical distancing, shapes public life in several ways. For example, across the neighbourhoods of Paddington and Red Hill, the following direct observations in public spaces have collected through the diary method in close vicinity of the researcher's residence made during the month of April. A significant increase in the number of people appropriating public open space within walking and cycling distance. This occurred at sports fields, shared path networks, nature strips, 
Observations on Death and Life of Public Space in Australia during the COVID-19 Pandemic

bush lands, local streets and footpaths. While parents teach their children how to ride bikes, others choose to play football, soccer, basketball or cricket in the middle of the streets.

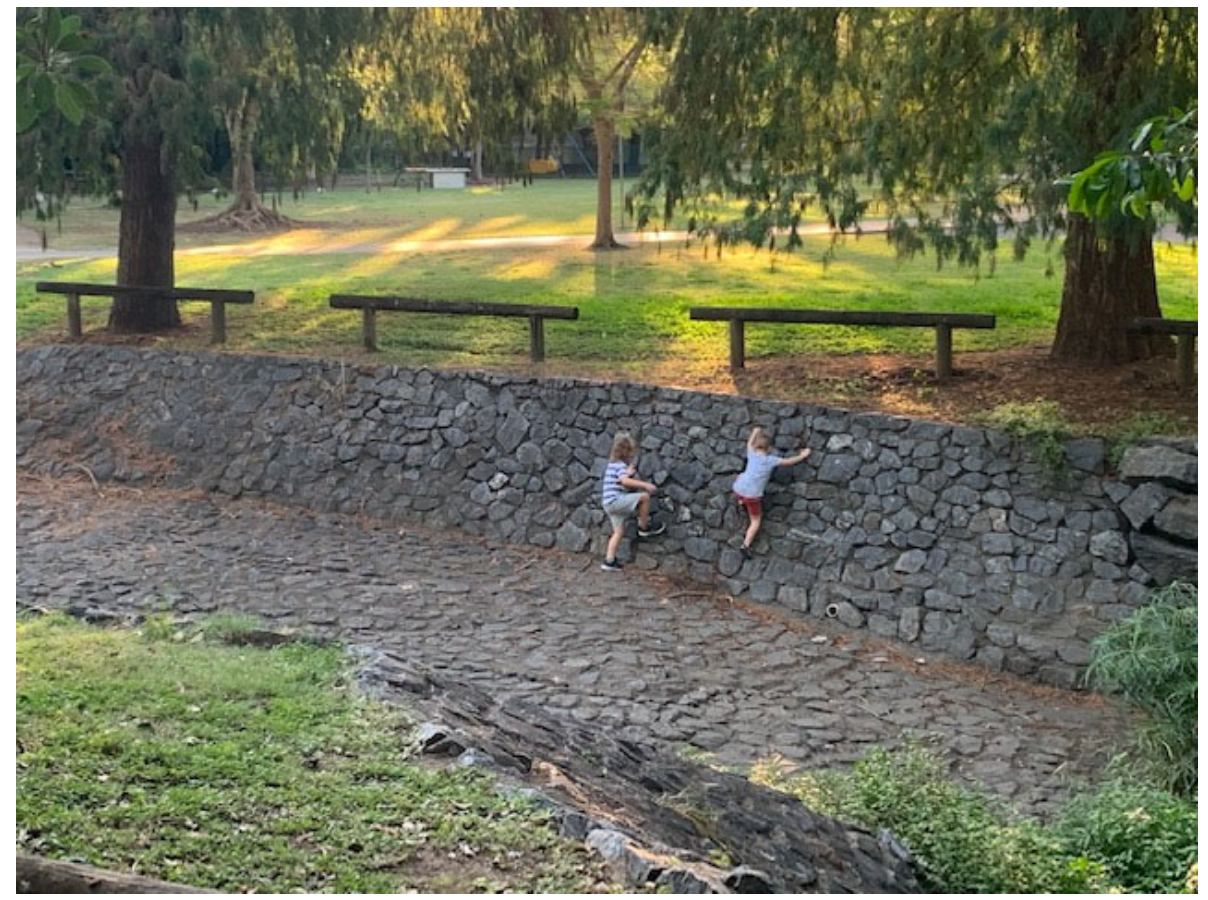

Figure 4. Rock climbing action of children in local open space (Source: Gregor Mews)

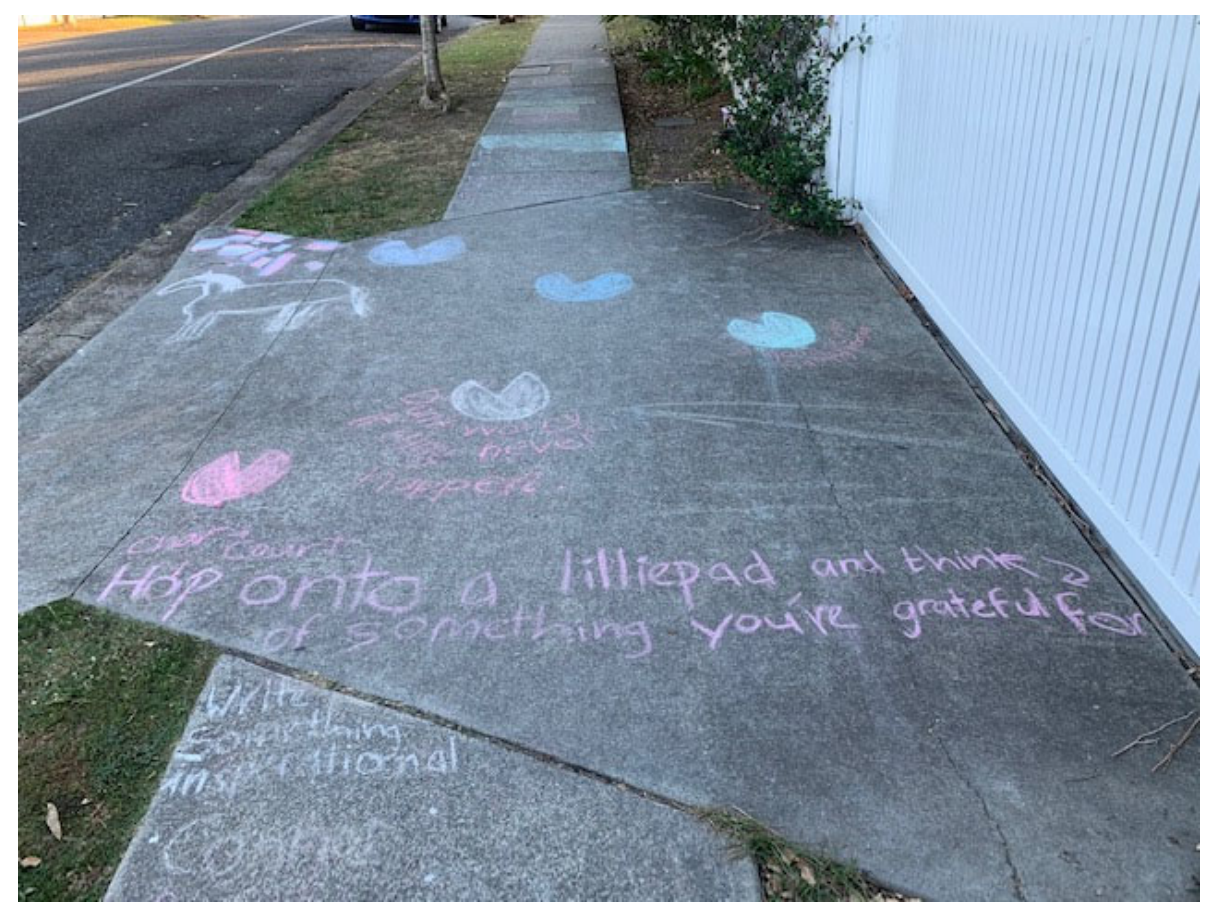

Figure 5. Invented street game during COVID-19 Lockdown (Source: Gregor Mews) 
Many walk their pets and enjoy sitting on benches, logs and fences while observing others passing by. Noticeably many more people sit consciously in their front yards or having dinner or picnic in their driveway in order to experience some sort of social cohesion. Physical props such as chairs, benches or stuffed animals decorate the yards as symbolic representation and celebration of solidarity with others. In addition, graffiti with positive messages are created by children or youth (Figure 3).

Especially children invent games to deal with the 'new normal' in creative ways. Games such as rock climbing (Figure 4) or Lillypad jumping (Figure 5) emerging as a form of grassroots 'tactical' urbanism.

\section{Observations from Ngunnawal Countryl Canberra}

Ngunnawal country also commonly known as Canberra is a place of a designed city build on the land of the Ngunnawal and Ngambri people. It is the capital of Australia with only 420000 inhabitants and considered a young city in its development (Australian Bureau of Statistics). Designed on the basis of garden city and city beautiful concepts, Canberra is considered the "Bush Capital" with endless suburbs as satellite centres and low-density living (Reid, 2002). Canberra has an abundance of open green spaces, the highest of all cities in Australia, with approximately 353 square meters of green space per capita (Australian Bureau of Statistics, 2017).

Direct observations in March and April during the social distancing measures are showing an increase in usage of local public spaces, for exercise, walking, biking, etc. The areas traditionally used for exercise such as for example the lake Burley Griffin have seen an increase also. We can observe intensification in the use of local public space. The traces of this trend can be seen in the children's graffiti messages on the pavement, or book reading exchange practices around the neighbourhood (Figure 6) as well as suburban bear hunt activities for children, and 'driveway project'.

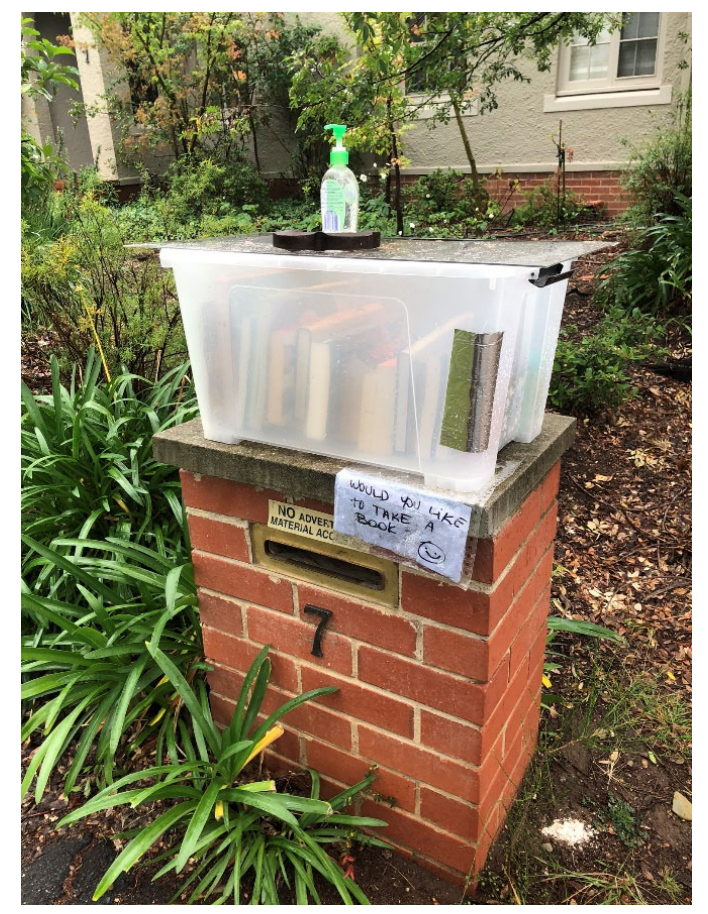

Figure 6. A neighbourhood book sharing initiative (Source: Milica Muminovic) 
Utilising social media to promote the neighbourhood, reinforce solidarity and a sense of community and activate the public space there are examples of individual leadership. For example, the bear hunting included people participating leaving a bear toy on the window for the children to go on 'hunt' for as many as they can spot. Generating a sense of community and solidarity. One other interesting example of the message sharing is located on the apartment building, where during the night the slide show is projected on the facade with different slides sharing the messages to the local community. The messages have been changing every week, for example there was a special message for Anzac Day and on ordinary days reflections related to everyday life (as in the example of Figure 7) all positive support to the community.
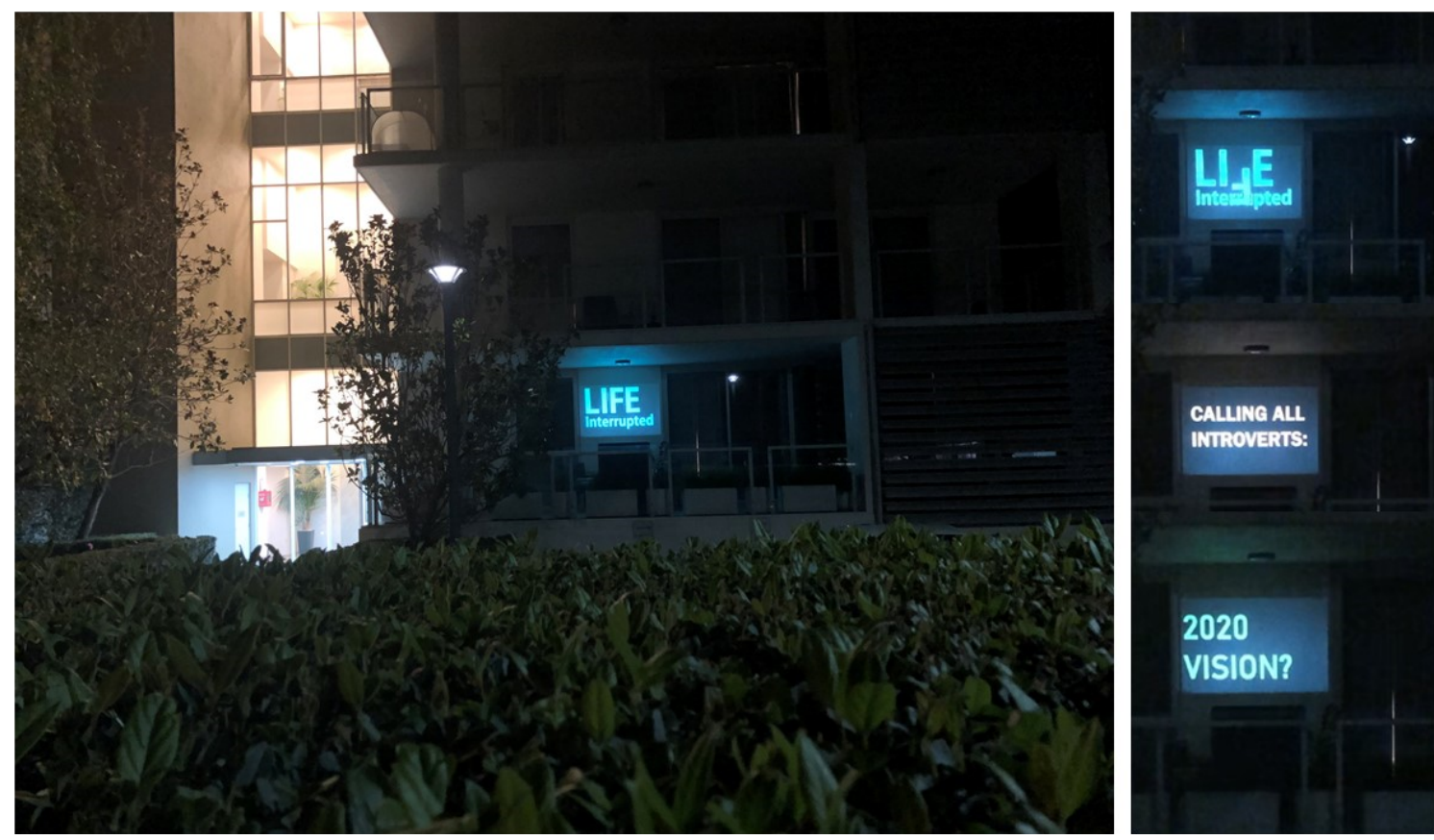

Figure 7. A neighbourhood screening on the façade with messages as short videos (Source: Milica Muminovic)

\section{Urban loveability and public space culture post-COVID I9}

Both case studies highlighted that many people are rediscovering and imbue their local neighbourhoods with public life. On the one hand, it might be too early to tell how COVID-19 is impacting everyday life beyond the novelty of re-experiencing the local. On the other hand, this extreme situation offers the opportunity to see the everyday life and the local suburban neighbourhoods in a different light. The spaces people were producing are not based on the pursuit of capital accumulation (Harvey, 2006). Could this situation offer a glimpse of a new way of interaction? Large community events are simply not possible under current restrictions and therefore it is too early to tell what type and how many new grassroots place-making activities might occur post lockdown. Furthermore, focusing on the very small details related to activities in public space might hold answers to questions related to what type of new spaces are being co-produced, 
how they contribute to a sense of community and function as mean to celebrate public life. All these are bringing us to question again small, local, ad-hoc, bottom-up ways of expressing the 'urban loveability' that can contribute to different ways of socialising, health and well-being, as well as belonging.

For example, the case of the invented street game, where people are encouraged to jump lily pads. Firstly, the preconditions were right. Parents were near-by and felt it is safe for their children to play on the street. Local vehicle traffic is currently exceptionally low, while many neighbours are also at home contributing to some sort of passive surveillance. Further, the creative process of producing drawings and patterns on flat surfaces meets the definition of 'urban loveability' as a voluntary, positive and intrinsic feeling to create something that is good for the maker as well as others. Once this space was socially produced, others were voluntarily engaged in the spirit of sharing or just observing, laughing and giggling. Arguably, human existence becomes meaningful with a sense of immediacy. Other examples, including the making of graffiti with positive messages or climbing on the walls follow the same process and outcome.

The optimism of Jane Jacobs can be shared, we as a design community have the right tools and know-how to help shape a 'new normal' in which the city as a conscious work of art can indeed emerge out of a collaborative and communal framework. This 'new normal' can be filled and enriched with many personalised forms of art as Mumford described it, and that transcends commodification in the service of capital accumulation and overcomes separation or alienation.

Unlike so many other societies, Australia experienced rather fortunate circumstances including low transmission rates that resulted in conditions that enable travel bubbles and a 'new normal' where most people regain confidence in the pre-COVID paradigm. In fact, in pursuit the compensation for the temporary losses that occurred during 2020, the society accelerated its efforts to reinforce a 'normal' that is again far away from what we observed during the lockdown. However, hope is what remains as it presents an opportunity for all to become conscious and accountable for our own actions and the impact of individual actions on others around us.

Ultimately, it is now up to each and every one of us to be brave, proactive in realising this shared potential. A realisation that a new ontological state of existence is obtainable. We should start by paying attention to the very small acts and deeds of everyday life in public spaces and nurture conditions that enable the possibility to bring out the very best in us. Only then we will be able to truly celebrate, share and lastingly value public spaces for all.

\section{References}

Amin, A. (2008). Collective culture and urban public space, City, I2 (I) 5- 24. DOI: 10.1080/13604810801933495.

Australian Bureau Of Statistics (2017). 2016 Census Community Profile [Online], Available: https://quickstats.censusdata.abs.gov.au/census_services/getproduct/census/2016/commu nityprofile/8ACTE?opendocument [Accessed I May 2020].

Australian Government (2020). Corona virus updates [Online], Available: https://www.australia.gov.au/coronavirus-updates [Accessed I May 2020]. 
Butler, C. (2012). Henri Lefebvre: Spatial Politics, everyday life and the right to the city, New York, NY, Oxon, OX, Routledge.

Debord, G. (1957). Report on the Construction of Situations and on the International Situationist Tendency's Conditions of Organization and Action., Paris, Bureau of Public Secrets.

Debord, G. (1983). The Society of the Spectacle, Cambridge, MA, London, UK, MIT Press.

Farrelly, E. (202I). Killing Sydney: The Fight for a City's Soul, Pan Macmillan Australia.

Gehl, J., Svarre, B. \& Steenhard, K. A. (2013). How to study public life, Washington, DC, Island Press.

Google (2020). Google COVID-1 9 Community Mobility Report [Online]. Google Available: https://www.google.com/covid 19/mobility/ [Accessed 23 April 2020].

Harvey, D. (1985). Consciousness and the urban experience: Studies in the history and theory of capitalist urbanization, Johns Hopkins University Press.

Harvey, D. (2006). The Political Economy of Public Space. In: LOW, S. \& SMITH, N. (eds.) The Politics of Public Space. London, UK: Routledge.

Jacobs, J. (I96I). The death and life of great American cities, New York, NY, Random House.

Lefebvre, H. (199I). Critique of everyday life, London, UK, New York, United States, Verso.

Mews, G. (2020). Urban loveability in a post-COVID-I9 world World Urban Campaign [Online]. Available from: https://www.worldurbancampaign.org/urban-synergies-group-urbanloveability-post-covid-19-world [Accessed 06/05/2020 2020].

Mumford, L. (20I6). The culture of cities, Open Road Media.

Ottosen, N. \& Mews, G. (2019). Exploring new horizons for youth wellbeing and Public Space in Sierra Leone. ISOCARP Review I5-Planning for Metropolitan area:, 332-349.

Population Australia (2020). Brisbane Population 2020 [Online]. Population Australia. Available: http://www.population.net.au/brisbane-population/ [Accessed 28 April 2020].

Zizek, S. (2020). Pandemic!: COVID-1 9 shakes the world, John Wiley \& Sons.

REID, P. 2002. Canberra following Griffin, A design history of Australia's National Capital. National Archives of Australia. 